\title{
Ensinar o que não se sabe: estranhar e desnaturalizar em relatos (auto)biográficos
}

Teaching what one does not know: strangeness and denaturation in (auto)biographical narrations

\author{
Jorge Luiz da Cunha* \\ Universidade Federal de Santa Maria \\ Joana Elisa Röwer** \\ Universidade Federal de Santa Maria
}

Resumo O foco temático deste texto são os processos de estranhamento/desnaturalização em relatos (auto)biográficos. O objetivo foi refletir sobre a possibilidade de fomentar estranhamentos/desnaturalizações em escritos (auto)biográficos por adolescentes no espaço/tempo de sala de aula. A proposta metodológica consistiu no desenvolvimento de relatos (auto)biográficos de estudantes nas aulas de Sociologia no Ensino Médio. Participaram 138 jovens de uma escola pública no primeiro trimestre escolar de 2013. As concepções de estranhamento/desnaturalização situam-se na antropologia; e, sobre o trabalho com relatos (auto)biográficos, nas perspectivas da socioclínica e dos processos de biografização. Os resultados indicam que os relatos (auto)biográficos proporcionam estranhamentos/desnaturalizações e rumam na direção de ensinar o que não se sabe. Conclui-se que essa possibilidade, como ato educativo, pode gerar suspensão de saberes para inventividades de si.

PALAVRAS-CHAVE: Relatos (Auto)biográficos, Estranhamento e desnaturalização, Educação

\begin{abstract}
The thematic focus in this text are the estrangement/denaturation processes in (auto)biographical narrations. The aim of this study was to reflect on the possibility to promote estrangement/denaturation in (auto)biographical writings made by teenagers in the space/ time of the classroom environment. The methodological proposal consisted on developing (auto)biographical writings by students from sociology classes in High School. A total of 138 teenagers from a public school, attending the first school trimester in the year 2013, have participated in the study. The concepts of estrangement/denaturation are located in the anthropology field and, the work with (auto)biographical narrations is located in the socio-clinic perspectives and of biographization processes. The results indicate that (auto)biographical narrations provide estrangements/denaturation and go towards teaching what one does not know. We can, then, conclude that this possibility, as an educational act, may generate knowledge suspension to self-inventiveness.
\end{abstract}

KEYWORDS: (Auto)biographical narrations, Estrangement and denaturation, Education. 
Morri aos dez anos de idade,

numa bela tarde de outono, numa luz que dá vontade de eternidade.

(MICHEL ONFRAY, 2010)

\section{Estranhamentos e desnaturalizações: aproximações teóricas}

O que é o estranhamento e a desnaturalização senão o confrontar-se? Pôrse frente a frente seja com outro exterior ou outro eu? Pôr-se frente a frente e enfrentar esse estranho que questiona, que perturba por excesso/por falta, que incide sobre a curiosidade e o desejo(?)e esse natural que molda, acomoda, incomoda(?). Estranhar/ desnaturalizar é um ato educativo, pois mobiliza e transforma. Exige revisão e reordenação de si. Estranhamento/desnaturalização como ato pedagógico visa a ampliação da visão de mundo e horizontes de expectativas de si nas relações sociais, pois contribui para o protagonismo ao desestabilizar e rearticular.

O estranhamento não é somente do outro, mas também de si. $\mathrm{O}$ espanto também acontece em situações que vivenciamos e diante de nossas próprias atitudes. A desnaturalização da nossa história de vida, do cotidiano, nos envolve enquanto sujeitos de conhecimento que são sempre sujeitos em relação. Assim desanaturalizar-se significa desnaturalizar o outro.

Estranhar/desnaturalizar são atividades de pensamento, movimentos que levam a outras formas de relação, de práticas. Estranhamento/desnaturalização, como ato pedagógico, configura-se como processos dissonantes, com fins indefinidos... Não é algo objetivado, concreto, pois relacionado a subjetividade com propósito de aquisição do próprio processo de estranhar/desnaturalizar em continuo. Essas reflexões se aproximam das concepções de Morin (2003) sobre a compreensão que requerem/ exigem o estranhamento, a incompreensão do outro que está em mim, na perspectiva de que, compreender o outro exige a compreensão de si (MORIN, 2002).

Nesse sentido, Christoph Wulf em diálogo com Morin sublinha:

A estranheza diante de si mesmo é uma experiência essencial, pois ela permite abrir-se as outras culturas, e ao outro. [...] o que é essencial é partir da não compreensão, de uma situação em que não compreendemos o estranho nem compreendemos a nós mesmos. A partir dessa incerteza temos uma atitude muito menos violenta com relação ao outro e com relação a nós mesmos. [...] é necessário partir da incompreensibilidade do estranho. Essa é uma posição extrema que torna supérfluo o uso da violência. (MORIN; WULF, 2003, p. 36-8)

Estranheza, (in)compreensão, incerteza palavras e efeitos que podem coadunar-se com a perspectiva da incompletude dos relatos (auto)biográficos. Bouillond (2011) aborda a questão da incompletude dos relatos (auto)biográficos quando afirma que "ele é incompleto nos dados, como toda ferramenta de coleta, mas não no plano da significação [...]" (BOUILLOND, 2011, p. 52). Isso porque o texto (auto)biográfico expressa coerência e autonomia, cabendo na análise a busca "do sentido do relato, daquilo que ele quer dizer para o autor" (BOUILLOND, 2011, p. 52).A análise do sentido e não de um dado objetivado é encontrada também em Pineau (2011), para o qual, a finalidade das histórias de vida é a construção de um sentido. 
Acreditamos também, que as revelações encontradas nas narrativas desvelam as emoções constituidoras do cotidiano, ou seja, marcado pela contraditoriedade, complexidade, fluidez dos sentimentos e emoções que deixaram marcas e que podem marcar. Ainda, concebemos as narrativas de vida, como expressa Pineau (2011, p. 32) "a história de vida em formação é um meio de perceber um percurso de vida em construção".

Aproximamos-nos dos conceitos e processos de estranhamento/desnaturalização através da perspectiva antropológica. Da Matta (1978; 1987), ao situar a Antropologia como uma ciência interpretativa, nos ajuda a pensar nestes conceitos/ processos ao discorrer sobre o que consiste em transformar o exótico no familiar e/ou transformar o familiar em exóticos como tarefas do etnólogo. Transformar o exótico no familiar significa a "busca de liberdade dos enigmas sociais situados em universos de significação sabidamente incompreendidos pelos meios sociais do seu tempo" (DA MATTA, 1978, p. 4), ou seja, se refere ao processo de estranhamento do outro e ao movimento de busca de compreensão.

Transformar o familiar em exóticos faz referência ao movimento próprio de "estranhar alguma regra social familiar e assim descobrir [...] o exótico no que está petrificado dentro de nós pela reificação e pelos mecanismos de legitimação" (DA MATTA, 1978, p. 5), é a desnaturalização do próprio grupo social de convívio, mas, que conduz também ao estranhamento e ao encontro com outro (DA MATTA, 1978). Ainda, para Da Matta (1978), estes dois movimentos encontram-se imbricados e não ocorrem de forma perfeita ou completa, pois a familiarização e o exotismo, o estranhamento e a desnaturalização, como processos, deixam resíduos. O exótico familiarizado permanece com resíduos do que é estranho e o familiar estranhado com resíduos de naturalidade.

Velho (1978) complexifica a ideia de distância e objetividade, na pesquisa antropológica, ao propor que não é a proximidade ou a distância que produz familiaridade ou exotismo, naturalidade ou estranhamento, necessariamente, e que estes simbolizem compreensões e incompressões. Velho (1978) afirma que em nossa sociedade complexa, hierarquizada, composta de esteriótipos sociais e anonimatos, plural e midiática a noção de familiaridade e exotismo é relativizada. $\mathrm{O}$ grau de familiaridade e exotismo entre grupos e pessoas não é homogêneo, pois a simples proximidade não significa conhecer os processos de funcionamento.

Mesmo Da Matta (1978) e Velho (1978) referindo-se ao ofício do etnólogo, tais reflexões servem como referência para pensar os conceitos e processos de estranhamento e desnaturalização que podem ser realizados não por cientistas, mas por pessoas no cotidiano. Velho (1978) situa a familiaridade como um tipo de apreensão da realidade, uma forma de interpretação e, assim, de produção de conhecimento. As pessoas, no seu cotidiano, também interpretam e produzem familiaridades e estranhamentos, o que varia é a base da argumentação e interpretação. Quando falamos em interpretações na cotidianidade, realizadas por pessoas que não se utilizam de um método científico, estamos falando de interpretações e argumentações embasadas no senso comum.

Geertz (2012, p. 79), ao situar-se na antropologia interpretativa, afirma que "os argumentos do senso comum, porém não se baseiam em coisa alguma, a não ser 
na vida como um todo. O mundo é sua autoridade". Se a realidade como vivida é a base da argumentação do senso comum que constitui os modos de interpretação das pessoas na cotidianidade, então o que pode ser estranhado/desnaturalizado senão o senso comum? Mas quais as possibilidades de compreensão do que é o senso comum?

Geertz, na sua obra $O$ saber local: novos ensaios em antropologia interpretativa (2012), escreve um capítulo intitulado "O senso comum como um sistema cultural". Compreender a abordagem de Geertz parte da prerrogativa que a análise da cultura não é "como uma ciência experimental em busca de leis, mas como uma ciência interpretativa, à procura do significado" (GEERTZ, 2008, p. 4), que parte de fatos pequenos, micros, mas densamente entrelaçados (GEERTZ, 2008).

Os acontecimentos microscópicos são um dos pontos de partida da análise da antropologia interpretativa. Quando analisa os acontecimentos, os casos, Geertz não parte de uma questão abstrata, de um conceito, de uma generalização. Como etnógrafo que produz uma descrição densa, o foco não está em responder questões nossas, mas sim revelar, colocar a disposição as respostas que outros deram as perguntas que fizeram. "A tarefa essencial da construção teórica não é codificar regularidades abstratas, mas tornar possíveis descrições minuciosas; não generalizar através dos casos, mas generalizar dentro deles" (GEERTZ, 2008, p.18).

Assim sendo, a análise cultural, fundamentalmente, constitui-se em um processo incompleto, pois é embasado na interpretação. Interpretações micros, em que da teoria é utilizado o vocabulário para dar expressão ao ato simbólico analisado, ou seja, o que ele diz dele mesmo. "O objetivo é tirar grandes conclusões a partir de fatos pequenos, mas densamente entrelaçados; apoiar amplas afirmativas sobre o papel da cultura na construção da vida coletiva empenhando-as exatamente em especificações complexas" (GEERTZ, 2008, p. 20).

Nesta perspectiva, o senso comum é interpretado como um sistema cultural, pois dotado de significados. No intuito de caracterizar o que é familiar, pois o senso comum nos é algo familiar Geertz (2012) acentua a necessidade de repensar a distinção do senso comum como uma mera apreensão da realidade ou como uma sabedoria coloquial. Para Geertz (2012), esta categoria é um produto histórico e, assim, o senso comum e o bom senso não são meras apreensões da realidade, mas interpretações da realidade imediata que proporcionam explicações aos fatos da vida, tendo a pretensão da veracidade.

A possibilidade de estranhar e desnaturalizar o senso comum, através dos relatos (auto)biográficos, remete a estranhar e desnaturalizar práticas cotidianas. O estranhamento e a desnaturalização, compreendidos como atos pedagógicos, imputa a possibilidade de deixar em suspensão modos cotidianos de ser/fazer/sentir/compreender.

\section{Estranhamentos e desnaturalizações: possibilidades práticas}

Respeitadas as diferenças, a experiência a ser relatada conversa com pressupostos de intervenção da socioclínica (TAKEUTI; BEZERRA, 2009, 2013) e processos de biografização/pesquisa biográfica em educação (DELORY-MOMBERGER, 
2011). Conversa porque não realiza uma socioclínica ou pesquisa biográfica em educação, apenas toma emprestados alguns pressupostos teóricos e metodológicos para refletir sobre a possibilidade de fomentar espaços/tempos de estranhamento/desnaturalizações através de relatos biográficos de adolescentes no espaço da sala de aula.

Primeiramente, é importante elucidar que a sociologia clínica opera com dispositivos de "trabalho de si", que são construídos e reinventados conjuntamente na relação entre participantes e pesquisadores na construção de um saber sobre uma determinada temática e sobre a própria experiência da pesquisa (TAKEUTI, 2009) (TAKEUTI; BEZERRA, 2009). Outras prerrogativas da socioclínica são da não hierarquização dos saberes entre os sujeitos pesquisadores e interventores provenientes da academia, e os participantes das ações desenvolvidas que revelam a cotidianidade da compreensão da pesquisa como práxis social, em que intervenção e pesquisa são processos indissociáveis e que "o conhecimento é co-produzido com os sujeitos da pesquisa e, simultaneamente, vinculados às situações reais e as vivências desses mesmos sujeitos" (TAKEUTI; BEZERRA, 2013, p. 6).

A socioclínica não se detém na compreensão de normas/normalidades, nem se propõem à terapia, mas ao desvelamento de sentidos em que a intervenção, através de dispositivos biográficos suscita espaços de reflexão, resignificações e recentramentos para "buscar os meios de saída para a sua situação de fechamento, através da possibilidade de pensar, de figurar formas outras de ser e atuar no mundo, para além daquilo que é dado, para além das expectativas sociais vigentes" (TAKEUTI; BEZERRA, 2013, p. 7). A sociologia clínica se caracteriza "sempre de trabalhos em campo que são de natureza da pesquisa-ação”(TAKEUTI, 2009, p. 77-8).

Os processos de biografização descritos por Delory-Momberger (2011) na relação com as pesquisas biográficas em formação têm uma dimensão definida entre biografia e aprendizagem. Como a socioclínica, elas não pretendem produzir saberes objetivados sobre os indivíduos que narram suas histórias de vida ou encontrar regularidades, mas compreender como jovens ou adultos "dão significados as suas experiências de formação e aprendizagem em suas construções biográficas individuais, nas suas relações com os outros e com o mundo social" (DELORY-MOMBERGER, 2011, p. 54).

Os processos de biografização, nas pesquisas biográficas em formação, tem como pressuposto que os saberes subjetivos e não formalizados influenciam no modo como as pessoas investem e transitam nos espaços de aprendizagens formais e que tornar-se cônscio destes saberes, torna possível resignificar sentidos e projetos de vida em formação (DELORY-MOMBERGER, 2006). Os processos de biografização implicam no estabelecimento da relação entre o social e o individual, a fim de questionar/ problematizar as construções biográficas mediante os condicionantes sociais, políticos, históricos, culturais.

As interrogações nos processos de biografização entre a construção e o saber sobre as histórias de vida e os contextos e processos de socialização nos interessa, especificamente, na propositiva de fomentar estranhamentos/desnaturalizações através de relatos (auto)biográficos, além da não intencionalidade de encontrar normas, normalidades e regularidades. Pretendemos indagar sobre a possibilidade dos efeitos dos relatos (auto)biográficos construídos dentro do espaço/tempo da sala de aula por 
jovens adolescentes a fim de produzir estranhamentos/desnaturalizações que levem a estados de suspensão de saber.

A hipótese é a de que trabalhar com relatos (auto)biográficos em sala de aula podem servir como uma abertura ao processo de questionar, em que o próprio ato de relatar-se produz estranhamentos/desnaturalizações. O relatar-se como ato pedagógico pode fomentar a ampliação da visão de mundo e horizontes de expectativas, e por isso tornar-se educativo, pois relacionado a suspensões de saberes e re-significações. Monteagudo afirma que:

Nos novos contextos globalizados, pós-modernos e cambiantes, as histórias de vida, como práticas multiformes de investigação, formação, intervenção social, testemunho histórico e construção de identidade, aspiram aprofundar uma maneira integradora e complexa de trabalhar para fazer mais viável o desenvolvimento da autonomia pessoal, a convivência tolerante e a participação social. (MONTEAGUDO, 2011, p. 81)

As reflexões de Monteagudo mostram quanto o trabalho com histórias de vida e/ou relatos (auto)biográficos podem ampliar e tornar mais significativos os processos de constituição dos sujeitos na perspectiva da autonomia das relações e da intervenção social. Refletir sobre a possibilidade de fomentar processos de estranhamento/ desnaturalização através de relatos (auto)biográficos como ato pedagógico refere-se a proporcionar espaços/tempos de reflexão e conscienciosidade dos sujeitos e dos seus conhecimentos sobre si. O relato como dispositivo biográfico e, antes, o processo de relatar-se pode ser compreendido com possibilidades de estranhamentos/ desnaturalizações, pois interroga e desestabiliza, gera abertura e suspensão de saberes.

Mas como provocar esses estranhamentos e desnaturalizações de si? Qual(is) questionamento(s) poderia(m) ser realizado(s) a fim de desestabilizar e por em suspensão os saberes sobre si, as práticas cotidianas, o senso comum que atravessa e conforma práticas e saberes? Uma questão apenas foi feita a estes adolescentes: quem é você? A simplicidade da questão que pode remeter a exigência de definição e identidade serviu como promotora de questionamentos, desestabilizações, estranhamentos/desnaturalizações e geradora de suspensões.

O contexto desse exercício, que ocorreu no início do ano letivo de 2013, foi em uma escola periférica, de um município de porte médio da região central do estado do Rio Grande do Sul/Brasil. Sendo que, 35\% da comunidade escolar (famílias) é considerada carente, pois, são beneficiadas pelo Bolsa Família. O bairro em que se localiza é caracterizado pela negatividade da violência e delinqüência e atende uma comunidade advinda de uma história de movimentos de luta pela moradia que derrocaram na invasão e ocupação das terras que originaram um dos bairros que a escola atende. Participaram 138 jovens, de ambos os sexos, de 14 a 18 anos. Os relatos foram escritos nas aulas de Sociologia, pois este exercício também vai ao encontro da especificidade desta disciplina de refletir sobre as biografias individuais na relação com os condicionantes sociais. Segue três dos relatos colhidos.

Quem eu sou? Uma pergunta muito difícil de responder, uma menina confusa e ao mesmo tempo bem decidida, às vezes muito vaidosa e em outras com uma grande preguiça para se arrumar, uma pessoa que adora dormir, mas que esquece à hora certa de fazer 
isso, a menina feliz que é marcada por essa característica. A menina confusa aqui ouviu muitos conselhos de amigos e da família, para fazer suas escolhas, mas por teimosia só ouviu o que achava que estava certo e o que não concordou talvez fosse o melhor a ser feito, mas não era o que lhe faria feliz naquele momento. Uma menina sonhadora sim, mas que de boba já não tem mais quase nada, que a família é a base mais forte, pois é eles que apesar de tudo acreditam no potencial que eu tenho e é para eles e principalmente para mim mesmo que pretendo a realização do meu objetivo. A menina que aprendeu muito com seus erros, e que leva pro seu futuro só o que foi bom, pra se tornar mais forte a cada dia. Espero que realize meus maiores desejos e o mais forte de todos nesse momento seria a conquista do vestibular nesse ano e conto com todos os amigos me dando força para isso. (Brenda, 17 anos, $3^{\circ}$ ano do ensino médio).

Minha vida cotidiana é um saco. Não saio pra lugar nenhum porque não tenho dinheiro e não tenho pra onde ir. Gostaria de trabalhar, não em qualquer emprego. Culturalmente as pessoas gostam de estudar, querem casar, ter três ou quatro filhos, virar dona de casa (as mulheres geralmente) e morar sempre no mesmo lugar com as mesmas pessoas; nada contra, mas isso já não serve pra mim. Não sei bem o que vou ser e fazer futuramente, tudo ainda é muito vazio, confuso e incerto, mas sei que quero ser independente, gostar do meu trabalho, talvez até aprender outra língua, ir para outro país, pelo menos é isso que eu gostaria que acontecesse. Não odeio meus pais, mas ás vezes me sinto melhor sem eles, somos diferentes demais, só que eu não posso fazer e dizer o que eu quero. Eles tentam, o meu pai, porque é com ele que eu moro, me mudar, me impedir de ser eu mesma, não completamente, mas se eu não aceito a sua opinião começa a me ofender, eu não me importo se ele fica contente ou não como o modo que eu ajo, mas não gosto que fique me dando lição de moral. Já sei pensar por mim mesma, sei que as coisas tem suas conseqüências, que as palavras das pessoas ignorantes ou desocupadas são perigosas, mas eu nunca fiz nenhuma grande bobagem; e nem pretendo fazer, ás vezes tenho ódio de mim mesma, mas prezo pela minha própria vida. Sou jovem mas estou cansada, me arrastando pois as dores da minha alma já alcançaram meu corpo, de certa forma é até algo bom, uma forma de amenizar a tristeza... Tenho esperança para o futuro, apesar de estar acostumada com as decepções pessoais e externas enfim, apesar de tudo... (Daniela, $1^{\circ}$ ano do ensino médio, 15 anos).

Meu nome é Paola, adoro esporte, amo jogar handebol, gosto de fazer educação física, gosto de dançar, mas em casa, por que eu ligo o som, curto a música e seja o que Deus quiser, eu sou colorada fanática mesmo, e podem dizer que o futebol é o "ópio do povo", como meu professor do ano passado me disse, que eu não ligo, não é porque eu gosto de assistir uma partida de futebol, que vou esquecer dos problemas sociais do país, que escolheram um papa, não é por que vai ter a copa no Brasil que vou achar esse país uma maravilha, são só noventa minutos para viver aquela emoção. Desculpa por ter perdido o foco, precisava fazer isso, não pude falar isso pra ele, por que ele era daqueles que não gosta de ouvir a opinião dos outros. Sou tímida, nem sei se é timidez, é um medo do que pensarão de mim, só sou "eu" em casa com a minha família, muito mais com a minha irmã, gosto de assistir filmes, ouvir músicas, de churrasco, 
não muito de mate. Sou uma adolescente de 16 anos, cursando o $2^{\circ}$ ano do ensino médio, quero muitas coisas, ter uma vida movimentada, com muita gente por perto, por que detesto a ideia de ficar sozinha, quero tempo para ver filmes, cursar uma faculdade, ter um emprego, tenho muitas incertezas e medos, medo de não conseguir um emprego, de não passar no vestibular, de não conseguir ser feliz. $\mathrm{Na}$ idade em que estou aprender é fácil, toda hora tem alguém te ensinando algo novo na escola, no rádio, com os amigos, na igreja, com os pais, com a minha irmã, algumas coisas me fazem pensar no por que de aprender isso ou aquilo, por que vou querer saber como se arava o arroz antigamente, como atuava um ator que morreu há anos, pra que saber como se faz um cachorro-quente, como se comporta um guepardo, pra que isso? Conforme os anos vão passando, percebo que é importante, em uma conversa com uma pessoa de mais idade, se tu não conhece nada de nada, o papo fica chato, você fica ouvindo sem parar, mas se seu pai já falou algo parecido sobre aquilo, você fica orgulhosa de poder conversar de "igual para igual", com alguém que viveu muito mais. Eu falei sobre ter aprendido a fazer cachorro-quente, e não é aquele pão e salsicha no molho, meus pais tem trailer de lanche, há nove anos, então aprendi a fazer um bom lanche, o fato de eu colocar isso no texto, está relacionado às minhas escolhas, o que vai ser do meu futuro, isso que os meus pais fazem interferem no que farei da vida. Eu quero muito cursar uma faculdade, me especializar, ter um trabalho, ser capaz de me sustentar, muita gente diz que agora é mais fácil entrar na faculdade, ter um bom emprego, que existem vários cursos técnicos a nossa disposição, mas para mim parece que está mais difícil, antes era assim, se meu pai fosse padeiro, padeiro eu seria, agora não, meus pais estão a nove anos trabalhando na rua para me dar a chance de estudar e ter um futuro mais fácil, mas aí eu penso no grande número de pessoas que escrevem melhor, e se eu entrar, me formar e não conseguir um emprego. Eu penso também no fato desse não querer fazer o que eles fazem, soa como se eu desmerecesse o que eles fazem. Lendo o que escrevi até agora e com base no que vivi nos últimos 16 anos com a minha família, eu percebo que, quem eu vou ser depende do que eu vou fazer com o que eu aprendi, eu posso não fazer nada e consequentemente chegar a nenhum lugar, ou eu posso tentar o vestibular até passar, buscar um emprego e viver, por que é assim a gente tem que viver, não dá pra simplesmente parar. (Paola, 16 anos, $2^{\circ}$ ano do ensino médio).

Estranhar/desnaturalizar o que se sabe sobre si, o que se escuta sobre si e deixar-se em suspensões para novas reorganizações, para uma prática de questionamentos em que a interrogação não versa somente sobre o outro, mas sobre si na relação com outros. Eis aí, talvez, uma tarefa da educação. Eis aí talvez uma aproximação do que Ranciére (2011) descreve em O mestre ignorante de ensinar o que se ignora. Pode-se tentar encontrar regularidades nos relatos, mas não é essa a propositiva, como também não é a de relacionar diretamente com suas aprendizagens escolares, mas sim provocar efeitos de questionamento, abertura e suspensão.

Assim também o que é estranhado e, o que é desnaturalizado e o que é deixado em suspensão não é algo a ser classificado, posto em categorias, mas dado as percepções individuais. Como escreve Ranciére (2011, p. 97) ao expor sobre o improviso e a fala, o ato de dizer-se, como caminhos para a emancipação de si "é preciso que 
o artesão fale de suas obras para se emancipar; é preciso que o aluno fale da arte que quer aprender".

Se Ranciére (2011) fala sobre ensinar o que não se sabe, Brandão (2002, p. 181) utiliza a expressão "deixados a si mesmo" ao refletir sobre a possibilidade criadora, imaginativa e simbólica de crianças e adolescentes que ocorre fora do âmbito do controle de incentivo e avaliação da escola, mas que esta captura ao enquadrar pedagogicamente a criação. Ensinar o que se ignora, deixar a si mesmo, fazer por conta pode parecer expressões transgressoras do ensinar-aprender, mas que podem constituir-se como atos pedagógicos pois viabilizam criações, (re)significações ou suspensões de saberes, como vimos pontuando.

Especificamente, em relação aos relatos (auto)biográficos, serve-nos aqui, compreensão que Certeau (1998) desenvolve sobre o relato. Tendo como objeto de pesquisa as práticas cotidianas, compreende o relato como um campo animado pela contradição entre a fronteira e a ponte, entre o legítimo e a exterioridade estranha. Certeau (1998) ao estudar os fazeres comuns da vida cotidiana desenvolve uma ciência da prática singular para identificar, descrever, analisar, comparar, compreender atividades ocultas e circunstanciais.

Desta forma, também é realizado um deslocamento da proposta de Certeau (1998), pois, como referido no texto, a ideia de fomentar a construção de relatos (auto) biográficos, no espaço da sala de aula, visando estranhamentos e desnaturalizações, não procura identificar, analisar, comparar o que é estranhado ou desnaturalizado. Têm-se apenas pressuposições do senso comum e de práticas cotidianas.

Contudo, Certeau (1998), amplia a concepção de relato como um guia e uma transgressão.

Eis aí precisamente o primeiro papel do relato. Abre um relato de legitimidade a ações efetivas. Cria um campo em que autoriza práticas sociais arriscadas e contingentes. [...] Os relatos são animados por uma contradição que neles representa a relação entre a fronteira e a ponte, isto é, entre um espaço (legítimo) e sua exterioridade (estranha). [...] Onde o mapa demarca, o relato faz uma travessia. O relato [...] instaura uma caminhada ("guia") e passa através ("transgride”). O espaço de operações que ele pisa é feito de movimentos: é topológico, relativo às deformações de figuras, e não tópico, definidor de lugares. O limite aí só circunscreve a modo de ambivalência. (CERTEAU, p. 210-215)

Pode-se então compreender os relatos como fronteiras que comportam outros? Como ainda no dizer de Certeau (1998, p. 215) que "no interior das fronteiras já existe o estrangeirismo, exotismo ou sabbat da memória, inquietante familiaridade tudo ocorre como se a própria delimitação fosse a ponte que abre o dentro para ser outro". Se sim, o importante é reconhecer que os relatos produzem efeitos de si para si, pois é uma "arte do dizer", "que produz então efeitos, não objetos. É narração, não descrição" (CERTEAU, 1998, p.154). E que estes, inseridos em um espaço escolar, podem gerar estranhamentos/desnaturalizações e promover aberturas, suspensões, resignificações. 


\section{Considerações...}

O que foi exposto nesse texto é uma proposta, uma possibilidade de trabalhar com relatos (auto)biográficos com jovens adolescentes no espaço da sala de aula, a fim de fomentar espaços/tempos de desnaturalização/estranhamentos de si para gerar suspensões de saberes. Suspensão também porque não se pretende construir rumos ou produzir alternativas que devam ser seguidas ou não, que são enquadradas entre o certo e o errado. Suspensão porque é esse estado de estranhar o que era familiar, de desnaturalizar o que estava posto, de também se aproximar com olhos abertos do estranho, do inquietante que produz outras interrogações e que põe em evidência o movimento.

Ao analisar a dinâmica experenciada, alguns elementos podem ser elencados como: (1) a não atribuição de sentido dos educandos em atividades que remetem as suas histórias individuais que pode ser compreendida tanto pelo viés de que atividades com estas características não resultam em conhecimento teórico e/ou de que refletir sobre suas biografias significa revelar trajetórias de vida marcadas por violência, abandono, carências econômicas e afetivas, onde a escola aparece como um lugar de saída dessas situações e não para reviverem tais configurações; (2) a relação educador -educando e a própria condição da pessoa do educador em trabalhar com trajetórias de vida de outros que envolve emocionalidades e demandas afetivas individuais, o que pode ser remetido a uma discussão tanto da função e da ética profissional do educador, quanto da formação docente, que não contempla tal preparação.

A compreensão dos relatos (auto)biográficos, como ato educativo através do estranhamento e da desnaturalização, rumam na direção de ensinar o que não se sabe ou ainda de deixar a si mesmo. Se a familiaridade é uma forma de interpretação da realidade e cotidianidade, o estranhamento e a desnaturalização produzidos pelos e nos relatos (auto)biográficos ao questionar saberes e práticas, apesar de serem atravessados pelo social e o cultural, podem ser deixados para que os próprios jovens adolescentes percebam seus estranhamentos, suas desnaturalizações e suas suspensões.

\section{Referências}

BOUILOUND, J. P. A autobiografia - um desafio epistemológico. In: TAKEUTI, N. M.; NIEWIADOMSKI, C. (Orgs.). Reinvenções do sujeito social: teorias e práticas biográficas. Porto Alegre: Sulina, 2009. p. 33-60.

BRANDÃO, C. R. A educação como cultura. Campinas, São Paulo: Mercado das Letras, 2002.

CERTEAU, M. A invenção do cotidiano. 3 ed. Petrópolis: Vozes, 1998.

DA MATTA, R. O ofício de etnólogo ou como ter Anthropological Blues. Boletim do Museu Nacional. Nova Série, Rio de Janeiro - Antropologia, no 27, p. 1-12, maio de 1978.

. Relativizando: uma introdução à Antropologia Social. Rio de Janeiro: Rocco, 1987.

DELORY-MOMBERGER, C. Formação e socialização: os ateliês biográficos de projeto.

Educação e Pesquisa. v. 32, n. 2, p. 359-371, maio/ago. 2006. Disponível em: <http://www. revistas.usp.br/ep/article/view/28015/29807>. Acesso em: 20 jul. 2013.

. Os desafios da pesquisa biográfica em educação. In: Memória, (auto)biografia e diversidade: questões de método e trabalho docente. SOUZA, E. C. (Org.). Salvador: EDUFBA, 2011. p. 43-58. 
GEERTZ, C. A interpretação das culturas. 1 ed. Rio de Janeiro: LTC, 2008.

. O senso comum como um sistema cultural. In: GEERTZ, C. O saber local: novos ensaios em antropologia interpretativa. 12 ed. Petrópolis, RJ: Vozes, 2012. p. 77-97.

MONTEAGUDO, J. G. As Histórias de vida em educação: Entre formação, pesquisa e testemunho. In: SOUZA, E. C. (Org.). Memória, (auto)biografia e diversidade: questões de método e trabalho docente. Salvador: EDUFBA, 2011.p. 59-96.

MORIN, E. Meus demônios. $3^{\text {a }}$ ed. Rio de Janeiro: Bertrand Brasil, 2002.

MORIN, E.; WULF, C. Planeta: a aventura desconhecida. São Paulo: UNESP, 2003.

PINEAU, G. Histórias de vida e alternância. In: SOUZA, E. C. (Org.). Memória, (auto)biografia e diversidade: questões de método e trabalho docente. Salvador: EDUFBA, 2011. p. $25-42$.

RANCIÉRE, J. O mestre ignorante: cinco lições sobre a emancipação intelectual. 3 ed. Belo Horizonte: Autêntica, 2011.

TAKEUTI, N. M. Desafios da abordagem socioclínica e biográfica no contexto sociocultural e político brasileiro. In: TAKEUTI, N. B. NIEWIADOMSKI, C. Reinvenções do Sujeito Social: teorias e práticas biográficas. Porto Alegre: Sulina, 2009. p. 74-94.

TAKEUTI, N. M. BEZERRA, M.A. Trajetórias de um coletivo jovem: nem só de prática-Gramática da Ira. In: TAKEUTI, N. B. NIEWIADOMSKI, C. Reinvenções do Sujeito Social: teorias e práticas biográficas. Porto Alegre: Sulina, 2009.p. 105-125.

Sociologia Clínica e Intervenção Comunitária. Extensão e Sociedade. Ano 3, n. 5, v. 1, 2012. Disponível em: <http://www.periodicos.ufrn.br/index.php/extensaoesociedade>. Acesso em: 15 jul.2013. p. 1-14.

VELHO, G. Observando o Familiar In: NUNES, E. de O. A aventura sociológica. Rio de Janeiro: Zahar, 1978. p. 1-13.

* Professor Doutor da Universidade Federal de Santa Maria, Santa Maria, Rio Grande do Sul - Brasil.

*** Doutoranda em Educação pela Universidade Federal de Santa Maria, Santa Maria, Rio Grande do Sul - Brasil.

\section{Correspondência}

Jorge Luiz da Cunha - Universidade Federal de Santa Maria, Av. Roraima, 1000, Camobi, CEP: 97105900, Santa Maria, Rio Grande do Sul - Brasil.

E-mail: jlcunha11@yahoo.com.br - joanarower@gmail.com

Recebido em 13 de outubro de 2013

Aprovado em 02 de dezembro de 2013 
